\title{
SISTEMATIZACIÓN COMPARATIVA DE LA REGULACIÓN DE LA FAMILIA EN LAS CONSTITUCIONES LATINOAMERICANAS*
}

\section{YANIRA ZÚNIIGA** Y SUSAN TURNER***}

RESUMEN: Este trabajo analiza el proceso de constitucionalización de la familia, en el marco de los textos constitucionales de la región americana, a fin de establecer sus tendencias regulativas más significativas, proponer lecturas interpretativas de este fenómeno y proveer insumos para discutir el rol constitucional de la familia en el Derecho chileno.

Palabras ClaVE: Constitucionalización - Constitución - familia derechos fundamentales - género.

\section{SYSTEMATIC COMPARISON OF THE REGULATION OF FAMILY IN LATIN AMERICAN CONSTITUTIONS}

ABSTRACT: This paper analyzes the constitutional process of the family, under the constitutions of the American region, in order to establish its most significant regulatory trends, propose interpretative readings of this phenomenon and provide input to discuss the constitutional role of the family in the Chilean law.

KEY WORDS: Constitutionalization - Constitution - family - gender fundamental rights.

Este trabajo forma parte del proyecto FONDECYT N ${ }^{\circ} 1110574$ que lleva por título $L a$ constitucionalización de la familia. Tendencias del Derecho comparado y desafios normativos para el Derecho chileno, y respecto del cual las autoras, en el orden que se consignan, son investigadora principal y coinvestigadora, respectivamente.

Fecha de recepción: 11 de marzo de 2013.

Fecha de aceptación: 29 de julio de 2013.

** Doctora en Derecho por la Universidad Carlos III de Madrid, Profesora de Derecho Constitucional y Derecho Internacional Público de la Universidad Austral de Chile. Correo electrónico: yzuniga@uach.cl

*** Doctora en Derecho por la Universidad de Göttingen, Profesora de Derecho Civil Universidad Austral de Chile. Correo electrónico: sturner@uach.cl 


\section{1) Planteamiento del problema}

Desde el punto sociológico, la familia tradicional ha sufrido en las últimas décadas cambios que la han impactado, tanto en lo relativo a su carácter de unidad económica como respecto de las relaciones emocionales que se desarrollan a su amparo ${ }^{1}$. Dichos cambios han sido múltiples, vertiginosos y globales; y los factores que los han catalizado son también diversos y transversales.

Entre estos últimos cabe destacar, en primer lugar, las transformaciones en la intimidad signadas por un deterioro del poder patriarcal, el declive del sexo reproductivo, el ascenso de la importancia social de los sentimientos y la erosión del matrimonio. Todo ello ha creado pulsiones para el desarrollo de relaciones más simétricas en el seno de las familias, caracterizadas por una intensificación del individualismo, en cierto desmedro de los tradicionales fines colectivos de esta institución ${ }^{2}$. Al mismo tiempo, este mismo proceso ha facilitado la diversificación de la familia que, aunque sigue anclada en el modelo de familia nuclear, exhibe en la actualidad múltiples formas (monoparentales, matrimoniales, no matrimoniales, fundadas en parejas heterosexuales, homosexuales etc.).

Desde luego, el ordenamiento jurídico ha debido, paulatinamente, hacerse eco de esos cambios. Así, por ejemplo, el desmantelamiento de la estructura patriarcal ha traído aparejado un cambio en la posición jurídica de los nińos y las mujeres, quienes habían sido tratados históricamente por las leyes civiles como incapaces relativos. En la actualidad, unos y otras se benefician de sendos procesos de individuación que conviven con la existencia de estatutos especiales de protección que recogen su situación de vulnerabilidad y discriminación, respectivamente.

Dentro de este escenario, mención especial requiere el fenómeno de emancipación de las mujeres por su notable repercusión en la regulación de la familia. Dicho fenómeno no solo ha generado un movimiento progresivo de igualación jurídica en el ámbito de la pareja -tanto dentro como fuera del matrimonio- ${ }^{3}$ sino que también ha contribuido a desdibujar el modelo clásico de hombres-proveedores y madres-cuidadoras, propiciando la eclosión de nuevas categorías de sujetos, tales como los ancianos y los discapacitados. Así, la combinación entre una mayor presencia de las mujeres en el mercado de trabajo y el envejecimiento demo-

Guiddens, Anthony (2000) Un mundo desbocado. Los efectos de la globalización en nuestras vidas, Capítulo 4. Madrid: Taurus, pp. 65-80.

2 Beck, U. y Beck-Gernsheim, E. (1998): El normal caos del amor. Traducción de Dorothee Schmitz, El Barcelona: Roure Editorial S.A. 292 pp.

3 Rodríguez Ruiz, Blanca (2012). "Paridad en lo doméstico: entre la normatividad y la realidad”. En Mestre i Mestre, Ruth y Zúñiga, Yanira (Coords.) Democracia y participación política de las Mujeres. Visiones desde Europa y América Latina. Valencia: Tirant lo Blanch, pp. 111-146. 
gráfico ha puesto en jaque la estructura tradicional de gestión del cuidado (cuidado de niños y de familiares dependientes) que ha estado históricamente radicada en las familias y, en especial, en las mujeres; empujando su desplazamiento hacia lo público a través del engrosamiento de las obligaciones prestacionales del Estado. En efecto, el sistema de cuidado informal fundado en la solidaridad familiar se ha vuelto eminentemente precario porque reposa sobre una estructura familiar de división de tareas que presupone la gratuidad del trabajo doméstico femenino y la inactividad laboral de las mujeres. Dicho modelo, sin embargo, está en franca retirada. El número de mujeres que se dedican exclusivamente al hogar ha disminuido estrepitosamente en las últimas décadas y, aunque la gran mayoría de quienes se han incorporado al mercado laboral divide su tiempo entre las labores domésticas y las labores remuneradas, resulta prácticamente imposible que las actuales trabajadoras realicen las funciones de cuidado con la misma dedicación de las otrora amas de casa. A lo anterior se suma que la gestión del cuidado o dependencia se ha vuelto cada vez más gravosa, tanto por su ingente costo como porque los tiempos dedicados a esta actividad se han multiplicado notablemente debido a la longevidad de las personas mayores. Todo ello ha generado crecientes demandas ciudadanas orientadas hacia la institucionalización de la gestión del cuidado y que reclaman la articulación de políticas públicas que permitan a las mujeres conciliar adecuadamente la vida familiar y laboral. Desde el punto de vista de los Estados, tales políticas buscan conjurar las amenazas que se ciernen sobre la estructura productiva estatal y la sostenibilidad del sistema de pensiones, dada la caída de las tasas de natalidad y la pérdida de ingresos que experimentan las familias ${ }^{4}$.

Así las cosas, la regulación constitucional de la familia se ha transformado en un verdadero colofón de un complejo proceso de transformaciones bidireccionales (desde lo social a lo jurídico y viceversa). A la clásica declaración política de que la familia es el núcleo fundamental de la sociedad, se han debido sumar, paulatinamente, un cúmulo de disposiciones sustantivas que, en sede constitucional, se ocupan de regular el rol de la familia, las relaciones que se dan entre sus miembros (usualmente con-

\footnotetext{
Sobre este aspecto puede consultarse Canóvas, Ana, Aragón, Jorge y Rocha, Fernando. (2005) «Las políticas de conciliación de la vida familiar y laboral en las Comunidades Autónomas». Cuadernos de Relaciones Laborales, Vol. 23, núm. 1, pp73-93, Lorenzo RoDRÍGUEz, Magdalena (2004) "La conciliación de la vida familiar y laboral en serio: apuntes constitucionales para una conciliación acorde con la igualdad y el principio de no discriminación". En Anuario Jurídico y Económico Escurialense, XXXVII, pp. 73-93 y LewIs, Jane (2000): "Estado de bienestar y trabajo no remunerado" en De Villota, Paloma (Ed.) La política económica desde una perspectiva de género. La individualización de los derechos sociales y fiscales en la Unión Europea. Madrid: Alianza Editorial, pp. 55-75; y Неnchoz, Caroline (2011) "Les politiques de conciliation famille-travail et l'égalité Réflexions sur le concept d'autonomie". Recherches sociologiques et anthropologiques, 42-2, pp. 173-187.
} 
figuradas en clave de derechos fundamentales) y las vinculaciones entre la familia, por un lado, y la sociedad civil y el Estado, por el otro. Como todo proceso emergente, este ha generado dificultades de interpretación y aplicación de las reglas jurídicas involucradas y tensiones entre las distintas orientaciones regulativas que tal proceso aglutina.

\section{1) La constitucionalización de la familia. Marco CONCEPTUAL}

La llamada constitucionalización del Derecho es un fenómeno expansivo que se irradia a las distintas ramas jurídicas, y que, desde hace ya un tiempo, ha llamado la atención de las doctrinas nacional ${ }^{5}$ y compara$\mathrm{da}^{6}$. La constitucionalización de la familia, en particular, implica un cambio de perspectiva en relación con la técnica de protección de la familia centrada en los cuerpos legales y tiene diversos significados.

Siguiendo a Millard ${ }^{7}$, es posible establecer tres significados posibles de la idea de constitucionalización de la familia. En primer lugar, la constitucionalización de la familia denota un subproceso dentro de la llamada constitucionalización del Derecho Civil. Este subproceso implica un progresivo abandono del modelo dicotómico moderno de lo público y lo privado, que dominó los siglos XIX y principios del XX, y que se caracterizaba por una regulación de la familia con sede exclusiva en la codificación civil; y, en su lugar, supone el desarrollo de una creciente intersección regulativa entre ambas esferas.

En segundo lugar, dicho proceso conlleva la existencia de normas de un cierto valor jerárquico en el sistema jurídico que se aplican a un objeto específico, en este caso, la familia. Estas disposiciones pueden estar contenidas en la Constitución o en otros cuerpos vinculados estrechamente a

5 Por ejemplo, Ferrada, Juan Carlos (Coord.) La Constitucionalización del derecho chileno. Santiago: Editorial Jurídica de Chile, 298 pp.

6 En este sentido, puede consultarse, Chávez Asencio, Manuel (1983) "Derechos familiares de la persona y derechos sociales de la familia", en Anuario del Departamento de Derecho de la Universidad Iberoamericana, Número 15, 1983, 109-139; Chávez Asencio, Manuel (2001) "La familia y los derechos humanos", Anuario del Departamento de Derecho de la Universidad Iberoamericana, Número 21, 168-185; y Chávez Asencio, Manuel (2002) "Derechos familiares fundamentales en Anuario del Departamento de Derecho de la Universidad Iberoamericana, Número 32, Sección de Previa, 2002, 185-201; Chávez Hernández, Efrén, "La protección constitucional de la familia; una aproximación a las Constituciones Latinoamericanas", ponencia presentada en el Instituto de Investigaciones Jurídicas de la UNAM, México, disponible en http://www.bibliojuridica.org/libros/5/2287/9.pdf.; LópezMuñIz, José Luis (2000) "La familia en la Constitución Española". Revista Española de Derecho Constitucional, N 58, enero-abril, 2000, pp. 11-43; y Rodríguez Ruiz, Blanca (2011). "Matrimonio, Género y Familia en la Constitución Española. Transcendiendo a la familia nuclear". Revista Española de Derecho Constitucional, No 91, enero-abril, pp. 69-102

7 Millard, Eric (2005), "Le droit constitutionnel de la famille". En Verpeaux, Michel (Editor). Code Civil et Constitution, París: Economica, 65-81. 
ella, por ejemplo el Derecho Fiscal, el Derecho Administrativo, el Derecho Social, etc. De ahí que el Derecho Constitucional de la familia no excluya al Derecho Civil sino que lo complemente. A diferencia del anterior, el Derecho Constitucional de la familia apunta a las políticas de la familia en un sentido amplio. En otras palabras, busca responder a las grandes preguntas relativas al lugar de la familia y su rol en el Estado y la sociedad.

Por último, el proceso en comento involucra también la aplicación de normas jurídicas a un objeto social que, como tal, no constituye ni un objeto jurídico específico de una rama determinada, ni un objeto susceptible de ser definido completamente por el ordenamiento jurídico. En este sentido, es evidente que la regulación de la familia, no es ni puede ser privativa de las leyes civiles ni de otras leyes, porque dichos cuerpos normativos solo tratan algunas de las cuestiones jurídicas asociadas a esta institución, de manera parcelada. De otro lado, la regulación constitucional, si bien proporciona elementos medulares que configuran el estatuto jurídico de las familias y de las relaciones familiares, no agota ni dicho estatuto ni mucho menos determina, desde un punto de vista sociológico, lo que una familia es o hace. En consecuencia, las disposiciones jurídicas que regulan la familia -tanto las legales como las constitucionales- configuran una construcción normativa híbrida, esto es, con caracteres didácticos e ideológicos. Por un lado, sus reglas buscan describir un conglomerado de relaciones típicas que socialmente son entendidas como una familia y, por el otro, prescribir, dentro de estas últimas, ciertos modelos especialmente deseables de dichas relaciones. En este sentido, tanto el Derecho Civil como el Derecho Constitucional de la familia son cuadros interpretativos dirigidos a los órganos de aplicación de tales normas.

Sin perjuicio de lo que se explica en el apartado siguiente, a propósito de la metodología de esta investigación, conviene aclarar que la emergencia de normas constitucionales que regulan de manera más o menos directa, la familia no agota todo el espectro de constitucionalización de esta, sino que se trata solamente de una dimensión de este fenómeno. En términos amplios, el fenómeno de constitucionalización de la familia comprende también un proceso de judicialización de las relaciones familiares en el marco de la jurisdicción constitucional comparada y de la jurisdicción internacional. Dicha judicialización ha sido jalada fundamentalmente por el potencial transformador del principio de igualdad y su aspecto más sobresaliente es el cuestionamiento de la heteronormatividad como elemento basal de la familia y de las relaciones que se dan bajo su alero.

La jurisprudencia de la Corte Constitucional colombiana que, desde el año 2007, ha extendido a personas homosexuales y transexuales derechos que eran exclusividad de familias o parejas conformadas por un hombre y una mujer; y la reciente decisión del Tribunal Constitucional chileno, en el marco de un procedimiento incidental de inaplicabili- 
dad, a propósito del art. 102 del Código Civil (Rol 1881-10, de fecha 03/11/2011); se inscriben en esta línea.

En el nivel internacional -como ya se dijo-dicha tendencia se replica. Así, por ejemplo, la Corte Europea de Derechos Humanos ha resuelto varios asuntos relacionados con la diversidad sexual y su vinculación con la vida familiar y el derecho al matrimonio. No obstante, la jurisprudencia de este órgano ha sido un tanto ambivalente. Por un lado, ha considerado que la decisión de un tribunal nacional de retirar a un padre homosexual la custodia de su hija menor de edad, con el argumento que la niña debería vivir en una familia tradicional para resguardar su interés superior, carecía de relación razonable de proporcionalidad entre la medida tomada y el fin perseguido (Salgueiro da Silva Mouta vs. Portugal, 1996), pero en lo concerniente a la aplicación de la igualdad a parejas homosexuales respecto del derecho al matrimonio, la Corte se ha mantenido fiel a su doctrina del margen de apreciación (p.e. Schalk et Kopf vs. Austria, 2010 ${ }^{8}$ ). En cambio, ha reconocido este último derecho a las personas transexuales (Goodwin vs. Inglaterra, 1997).

En el ámbito interamericano, la sentencia recaída en el caso Atala Riffo y niñas vs Chile (24.2.2012) constituye la primera decisión de la Corte Interamericana de Derechos Humanos referida a la prohibición de discriminación por razón de orientación sexual, en el contexto de las relaciones familiares. En esta decisión la Corte Interamericana sostuvo enfáticamente que la diferenciación fundada en la orientación sexual de una persona es contraria a la Convención Americana de Derechos Humanos porque "si bien es cierto que ciertas sociedades pueden ser intolerantes a condiciones como la raza, el sexo, la nacionalidad o la orientación sexual de una persona, los Estados no pueden utilizar esto como justificación para perpetuar tratos discriminatorios" $y$, al contrario, están internacionalmente obligados a adoptar las medidas que fueren necesarias para hacer efectivos los derechos establecidos en la Convención.

De lo expuesto hasta aquí puede colegirse, entonces, que la constitucionalización de la familia es un fenómeno normativo extremadamente complejo, que se desenvuelve en varias dimensiones regulativas (yuxtapuestas y disímiles), cumple diversas funciones normativas e involucra desafíos de articulación entre diferentes paradigmas.

A efectos analíticos resulta preferible, en consecuencia, examinar algunas parcelas de este fenómeno a fin de delinear adecuadamente sus rasgos distintivos con miras a componer en el futuro una visión de conjunto. Los fundamentos de esta aproximación metodológica se explican en la sección siguiente.

8 Con todo, en el caso Schalk et Kopf vs Austria, la Corte Europea también dio un giro en relación a su jurisprudencia anterior, reconociendo la aplicación a las parejas homosexuales del derecho a protección de la vida familiar (art. 8 Convenio) y no solo el derecho de protección de la vida privada, como venía sosteniendo en su jurisprudencia previa. 


\section{2) APUNTES METODOLÓgICOS}

\subsection{1) Objetivos e hipótesis}

De aquí en adelante este trabajo se concentra en indagar y caracterizar uno de los aspectos constitutivos del proceso de constitucionalización de la familia antes descrito. A saber, la regulación de la familia en el marco de las Cartas constitucionales y, en particular, sus rasgos distintivos en el ámbito latinoamericano. Partiendo de la base que las Constituciones son un reflejo más o menos fiel de las sociedades, se eligió América Latina porque en esta región se han producido en las últimas décadas reformas profundas a los textos constitucionales. Tales reformas han generado ventanas de oportunidad para la regulación constitucional de las transformaciones sociales obradas en la familia.

Por otra parte, debido a las similitudes culturales e histórico-políticas, las tendencias de regulación constitucional de la familia en el ámbito regional americano parecen ofrecer insumos útiles para emprender una reflexión crítica de la dirección que puede adoptar un proceso similar en el ámbito chileno. Con todo, el análisis específico de esta última cuestión no forma parte de este trabajo dado que este se mantiene en los contornos de una investigación preliminar de tipo exploratorio.

Para construir una hipótesis de trabajo que guiará el análisis así delineado, se tomó como punto de partida la caracterización que la cientista política norteamericana Mala Htun ha realizado sobre las reformas jurídicas a la familia en América Latina, y que, a la sazón, es el único estudio que se refiere, desde una perspectiva comparativa, a los contextos sociopolíticos que determinaron la eclosión de las primeras grandes transformaciones en el derecho de familia, en esta parte del hemisferio.

En su estudio comparado sobre Brasil, Argentina y Chile?, Htun analiza las reformas liberalizadoras de la familia obradas en las últimas tres décadas del siglo pasado en dichos Estados y evalúa el impacto que en ellas tuvieron los siguientes factores: a) la transición de dictadura a la democracia, b) las relaciones entre la Iglesia y el Estado, c) los esfuerzos de reformistas liberales y feministas y d) la influencia de las normas internacionales. La autora concluye que los procesos de modernización económica y estatal, impulsados por los gobiernos dictatoriales en las últimas décadas del siglo XX en América Latina, permitieron - de manera paradójica- la reforma de la familia en clave de equidad de género, toda vez que la subordinación de la mujer en este espacio era vista como un resabio que impedía el desarrollo social y económico. Lo anterior, unido a que los

\footnotetext{
9 Htun, Mala (2010), Sexo y Estado. Aborto, divorcio y familia bajo dictaduras y democracias en América Latina. Santiago (Chile): Ediciones Universidad Diego Portales, 278 pp.
} 
gobiernos militares de estos tres países se valieron de la asesoría de especialistas para elaborar esta nueva regulación, abrió la puerta a las tendencias normativas internacionales en la materia y a las demandas de equidad de género provenientes de los movimientos feministas. Este fenómeno repercutió directamente en algunas reformas de equidad de género dentro de la familia matrimonial (el establecimiento de la capacidad de la mujer casada o el reconocimiento de derechos patrimoniales dentro del matrimonio) y facilitó la regulación del divorcio vincular pese a la oposición de la Iglesia. Sin embargo, no logró vencer las resistencias conservadoras en lo concerniente a la regulación de los derechos sexuales y reproductivos y, en particular, respecto de la despenalización del aborto, incluso bajo los gobiernos democráticos.

Tomando en cuenta los datos aportados por la referida investigación se consideró, como hipótesis de trabajo, que la expansión de la democratización en América Latina durante estas últimas décadas, así como la existencia de varios casos de procesos constituyentes en la región (Bolivia, Ecuador, Venezuela) han generado un escenario normativo propicio para el reconocimiento constitucional de la diversificación social de la familia y el afianzamiento de los procesos de igualación emprendidos previamente por las leyes civiles.

Esta investigación busca establecer, entonces, cuáles de las transformaciones jurídicas iniciadas en los tres últimos decenios del siglo pasado a nivel legal se han afianzado a través de las actuales normas constitucionales de la región americana y explorar, además, cuál es el estado de avance en lo concerniente a la regulación específica de los derechos sexuales y reproductivos en las Constituciones, asunto que aparece -según expone Htun- como un verdadero nudo gordiano en la región. Se consideró también -como lo hace la autora- el impacto de las normas internacionales en este proceso. Para ello se elaboraron diferentes criterios asociados a tendencias en el plano sustantivo, los que se detallan más abajo.

Dado que la protección de los individuos en sede constitucional se realiza usualmente a través del establecimiento, por una parte, de posiciones jurídicas categorizadas como derechos fundamentales y, por la otra, de obligaciones estatales correlativas, se estimó relevante también levantar criterios de análisis de tipo formal. Estos últimos están orientados a caracterizar el diseńo que cada uno de estos textos constitucionales contiene respecto de los vínculos entre la familia, los individuos y el Estado, según se explica más adelante.

\subsection{2) Corpus de la investigación}

El corpus de esta investigación está constituido por un total de 19 Constituciones de la región americana. A saber, las Constituciones de 
Argentina (1994), Bolivia (2009), Brasil (1988), Colombia (1991), Costa Rica (1949), Cuba (1976), Ecuador (2008), El Salvador (1983), Guatemala (1993), Haití (1987), Honduras (1982), México (1917), Nicaragua (1986), Paraguay (1992), Perú (1993), República Dominicana (2010), Uruguay (1967) y Venezuela (2009).

Se excluyó a la Constitución chilena porque, como es sabido, esta no registra una modificación en materia de familia durante todo el período democrático y constituye, en este sentido, una excepción en la región. Por otra parte, la Constitución chilena es extraordinariamente ensuficiente lo concerniente a la de la familia. Pese a que el artículo $1^{\circ}$ inciso $2^{\circ}$ le asigna a esta el rol de "núcleo fundamental de la sociedad", en general, el texto chileno no contiene un estatuto sistemático sobre esta institución que pueda orientar la regulación que de ella hace el legislador, a efectos de atribuir derechos y obligaciones a sus miembros, ni las consecuencias jurídicas que derivan de la especial posición del Estado como garante de aquella. La hipertrofia abstencionista del constituyente original sumada a una regulación fragmentaria de la familia a nivel legal, han provocado una protección insuficiente y dispar de esta institución en el ordenamiento chileno ${ }^{10 .}$

Por lo mismo -y conforme se advirtió más arriba- una investigación como la planteada busca obtener insumos para emprender un desarrollo dogmático posterior que permita avanzar en la construcción de un concepto sustantivo de familia, coherente con los fines arquitectónicos que la Constitución chilena predica de esta institución y compatible con los derechos de sus miembros.

\subsection{3) Tendencias y criterios}

Como se adelantó previamente, se establecieron dos órdenes generales de criterios que se corresponden con sendas tendencias: tendencias en el plano sustantivo y tendencias en el plano formal. Cada una se compone de una serie de subcriterios elaborados tomando como base la caracterización hecha por el texto de Htun y por la doctrina nacional (principal-

10 En este orden de ideas, debe recordarse que la legislación chilena contempla, además de la familia matrimonial clásica regulada por el legislador civil y que concentra la plenitud de la protección estatal, normas de protección parcial para los miembros de familias extramatrimoniales. Así por ejemplo, la ley de violencia intrafamiliar considera a los convivientes para efectos de definir su ámbito de protección mientras que el artículo 390 del Código Penal se refiere a estos a los efectos de tipificar el delito de parricidio y el delito de femicidio. También la legislación de seguridad social contempla una tutela fragmentaria que consiste en la extensión del derecho a obtener pensiones a la conviviente sobreviviente siempre y cuando esta haya sido madre de un hijo reconocido del causante y haya vivido a sus expensas. Todo lo anterior compromete seriamente la real vigencia del principio de igualdad ante la ley, afecta el goce de derechos fundamentales que la propia Constitución atribuye a las personas y merma la autonomía de los sujetos para realizar sus propios planes de vida, aspectos todos consustanciales a la existencia de un Estado liberal. 
mente privatista), en torno a las transformaciones fundamentales operadas en la regulación de la familia a nivel comparado, tanto en el marco de las leyes civiles como en la regulación constitucional reciente ${ }^{11}$.

Así, las tendencias y subcriterios utilizados, en cada caso, son los siguientes:

\subsubsection{1) Tendencias en el plano sustantivo:}

- Desvinculación entre familia y matrimonio. Esta tendencia se expresa tanto en la equiparación de la filiación matrimonial con la filiación extramatrimonial, como a través del reconocimiento de formas alternativas a la familia matrimonial. Esta últimas comprenden a las uniones de hecho heterosexuales y homosexuales.

- Liberalización del divorcio. Esta tendencia no solo implica la regulación del matrimonio como vínculo esencialmente disoluble, sino también la liberalización del mismo, lo que se traduce en una consideración marginal del divorcio por falta y, como contrapartida, en el robustecimiento de una suerte de "derecho al divorcio" que opera sobre la base de la voluntad unilateral de los cónyuges.

- Desmantelamiento del modelo de familia patriarcal. Se consideraron reflejo de esta tendencia, entre otras disposiciones, aquellas que establecen relaciones de igualdad entre cónyuges y respecto de la filiación, las que confieren derechos especiales para mujeres y niños; las que reconocen la existencia de otros sujetos de derecho o destinatarios de protección; y las que suponen el establecimiento de relaciones de igualdad entre cónyuges y respecto de la filiación.

- Pérdida de importancia del rol reproductivo de la familia. Esta tendencia se relaciona con el reconocimiento de los derechos sexuales y reproductivos de los individuos, particularmente los relativos a la planificación familiar.

11 En este sentido, puede consultarse, Barrientos, Javier; Novales, Aranzazu (2004), Nuevo derecho matrimonial chileno. Santiago: LexisNexis, 427 pp.; Corral Talciani, Hernán (2004). "Familia sin matrimonio o familia sin familia", Revista Chilena de Derecho, Vol. 21 N$^{\circ}$ 2, 1994, pp. 259-272; Corral Talciani, Hernán "Claves para entender el Derecho de Familia Contemporáneo”, Revista Chilena de Derecho, Vol. 29 N 1, 2001, pp. 25-34; EICHLER, Margrit (1999) “Cambios familiares: familias, políticas e igualdad de género" en Facio, Alda y Fries, Lorena (Eds.), Género y Derecho. Santiago de Chile: LOM-la Morada, pp. 444-486; Kemelmajer de Carlucci, Aída (2005) "Codificación y Constitucionalización del Derecho Civil”. En VVAA. Sesquicentenario del Código Civil de Andrés Bello: pasado, presente y futuro de la codificación, Santiago, LexisNexis, Tomo II, 1193-1214; Schmidt, Claudia (2005). "La Constitucionalización del derecho de Familia", en VVAA. Sesquicentenario del Código Civil de Andrés Bello: pasado, presente y futuro de la codificación. Tomo II. Santiago: LexisNexis, pp. 1235-1244; y Serna, Pedro. "Crisis de la familia europea: una interpretación” (1994). Revista Chilena de Derecho, Vol. 21 N², pp. 233-244. 
- Internacionalización de la protección de la familia y de los derechos de sus miembros. Se expresa a través de mecanismos de reenvío y/o recepción de las normas internacionales que regulan la materia.

\subsubsection{2) Tendencias en el plano formal:}

- El desarrollo de una técnica constitucional de tratamiento de la familia que tiende a una regulación de esta institución de una manera más o menos exhaustiva. Se agruparon bajo esta tendencia las Constituciones que contienen un desarrollo detallado del estatuto constitucional de la familia, en muchos casos, por la vía de capítulos o secciones dedicadas en exclusiva a esta institución. A estas últimas le llamaremos maximalistas, para distinguirlas de aquellas que contienen una regulación, más bien básica o medular, a las que denominaremos minimalistas.

- Regulación constitucional de la familia en clave colectivista o en clave individualista, según si el texto constitucional regula la familia bajo epígrafes relacionados con derechos sociales, económicos, culturales etc., o, en cambio, en el marco de derechos calificados como "individuales". La mezcla de ambas visiones, da origen a aproximaciones mixtas.

\section{2) Sistematización de las CONSTituciones en AMÉRica lati- NA. TENDENCIAS EN EL PLANO FORMAL}

La aplicación de los criterios de sistematización de los textos constitucionales latinoamericanos descritos en la sección anterior, arroja el siguiente diagnóstico en el plano formal:

\section{1) REGULACIONES MAXIMALISTAS Y MINIMALISTAS}

Desde el punto de vista de la extensión de la normativa constitucional referida a la familia, las Constituciones analizadas pueden agruparse según si pretenden agotar todos o la gran mayoría de los aspectos de la familia (Constituciones maximalistas) o si, por el contrario, solo abordan algunos de ellos (Constituciones minimalistas), bajo la premisa de que una regulación global es imposible o inconveniente o de que el objeto de regulación está disponible para su tratamiento legislativo. A su vez, pueden acometer su tarea de dos maneras: consagrando especialmente un acápite (cualquiera sea su nivel: título, capítulo, párrafo, etc.) relativo a la familia o incluyendo la regulación en otro apartado. 
La regulación latinoamericana, entonces, puede presentar cuatro variantes: maximalistas, con y sin acápite especial, por una parte, y minimalistas, con y sin acápite especial, por la otra. Según estos criterios, el resultado del análisis es el siguiente:

2.1.1 De las 19 Constituciones analizadas, 14 son maximalistas (Bolivia, Brasil, Cuba, Colombia, Ecuador, Guatemala, Honduras, Nicaragua, Panamá, Paraguay, Perú, República Dominicana, Salvador y Venezuela) y solo 5, minimalistas (Argentina, Costa Rica, Haití, México, y Uruguay).

2.1.2 Las Constituciones maximalistas, por regla general, contienen un acápite especial para regular la familia. Excepcionalmente, Honduras, Colombia y Perú, siendo maximalistas, no tienen sus normas en acápite especial. Adicionalmente, en los casos de Guatemala y Colombia, las Constituciones contienen una norma general en su Título I. Las Constituciones minimalistas, por regla general, no contienen un acápite especial. Excepcionalmente, Haití, siendo minimalista, tiene el título X "De la familia”. Por consiguiente, actualmente existe un claro predominio de la tendencia maximalista, y dentro de ella, de la regulación de la familia bajo un acápite especial.

2.1.3 Se aprecia, dentro de ambos grupos de Constituciones, diferentes intensidades de maximalismo y minimalismo. De entre las regulaciones maximalistas, cabe destacar como extremas, por ejemplo, las de Brasil y Honduras. La primera de ellas se refiere, incluso, a la regulación que la ley hará de los paseos públicos y de los edificios de uso público y la fabricación de vehículos de transporte colectivo, a fin de garantizar el acceso adecuado a las personas portadoras de deficiencia (art. $227 \mathrm{~N}^{\circ}$ 2). La segunda, explicita el deber de los medios de comunicación de cooperar en la formación y educación del niño (art. 125). En general, las regulaciones maximalistas abordan materias que en el derecho chileno son tratadas por la ley. En efecto, materias tales como el desarrollo de los derechos y deberes personales entre cónyuges o entre los padres y los hijos, la regulación del patrimonio familiar, de la adopción, del límite de edad para la irresponsabilidad penal, etc., son aspectos que en nuestro ordenamiento son típicamente legales y no constitucionales.

2.1.4 También se aprecia, sobre todo entre las Constituciones maximalistas, un distinto énfasis en la concepción de la sociedad y del Estado que las inspira. Mientras en la mayoría no existen alusiones a estas concepciones y más bien se nota una clara influencia liberal, materializada en derechos fundamentales reconocidos a 
los miembros de la familia; en las Constituciones de Cuba y Venezuela se aprecian los valores asociados al deber de los padres de "contribuir activamente a su educación [de los hijos] y formación integral como ciudadanos útiles y preparados para la vida en la sociedad socialista", de "la educación patriótica y la formación comunista de las nuevas generaciones y la preparación de los niños, jóvenes y adultos para la vida social" y de la formación integral de la niñez y la juventud a la que deben prestar especial atención "la familia, los órganos estatales y las organizaciones de masas y sociales" (art. 38, 39 c. y 40 Constitución de Cuba) y la concepción de que "el Estado protegerá a las familias como asociación natural de la sociedad y como el espacio fundamental para el desarrollo integral de las personas" (art. 75 Constitución de Venezuela).

2.1.5 Se aprecian distintos grados de minimalismo, en el sentido que algunas Constituciones son especialmente parcas en los términos de sus regulaciones y en cambio otras, sin perder su carácter de minimalistas, abarcan mayor cantidad de aspectos relativos a la familia. Así, mientras Argentina solo se refiere a que la ley "establecerá la protección integral de la familia; la defensa del bien de familia; la compensación económica familiar y el acceso a una vivienda digna" (art. 14bis), la Constitución de Haití alude taxativamente a la protección de la familia como base fundamental de la sociedad (art. 259), a la familia matrimonial y no matrimonial, a la maternidad, a la infancia y ancianidad (art. 260 y 261) y al acceso a los tribunales y organismos de protección (art. 262).

\section{2) CONSTITUCIONES INDIVIDUALISTAS Y COLECTIVAS}

En atención a si la regulación de la familia en las Constituciones se establece a propósito de los derechos individuales o de los sociales, ellas pueden catalogarse de individualistas y colectivistas. Para mayor nitidez de este criterio de clasificación, no se consideraron aquellas Constituciones que, formalmente, no regulan la familia ni bajo un rótulo de derechos individuales ni bajo el de derechos sociales o colectivos. Conforme a lo anterior, la investigación arrojó los siguientes resultados:

2.2.1 Todas las Constituciones que regulan la familia a propósito de los derechos fundamentales, lo hacen en los derechos sociales y no en los individuales. En este sentido, por ejemplo, la Constitución boliviana que trata los "derechos de la niñez, la adolescencia y la juventud" (sección V), los "derechos de las familias" (sección VI), "derechos de las personas adultos mayores" (sección VII) y "los derechos de las personas con discapacidad" (sec- 
ción VIII), bajo el Capítulo V que regula los derechos sociales y económicos.

2.2.2 En aquellos casos en que la familia está regulada en un acápite especial, que no se encuentra ni dentro de los derechos colectivos ni de los individuales, el encasillamiento en cualquiera de las dos categorías se torna discutible porque requeriría de interpretación según el contenido de la regulación. Se encuentran en esta situación las Constituciones de Brasil, Cuba, Nicaragua, Panamá, México, Haití, República Dominicana, Argentina y Uruguay.

2.2.3 Se nota una tendencia consistente en que mientras más desarrollado está el enfoque colectivista de la familia, las normas contienen más habilitación para la creación de políticas públicas de prestación de servicios por parte del Estado. En este sentido, la Constitución de Perú establece que "la comunidad y el Estado protegen especialmente al nińo, al adolescente, a la madre y al anciano en situación de abandono. También protegen a la familia y promueven el matrimonio. Reconocen a estos últimos como institutos naturales y fundamentales de la sociedad" (art. 4 inciso 1 ); que "la política nacional de población tiene como objetivo difundir y promover la paternidad y maternidad responsables. Reconoce el derecho de las familias y de las personas a decidir. En tal sentido, "el Estado asegura los programas de educación y la información adecuados y el acceso a los medios, que no afecten la vida o la salud" (art. 6 inciso $1^{\circ}$, primera parte) y que "el trabajador tiene derecho a una remuneración equitativa y suficiente, que procure, para él y su familia, el bienestar material y espiritual. El pago de la remuneración y de los beneficios sociales del trabajador tiene prioridad sobre cualquiera otra obligación del empleador. Las remuneraciones mínimas se regulan por el Estado con participación de las organizaciones representativas de los trabajadores y de los empleadores" (art. 24). Otros ejemplos están dados por la Constitución de Honduras, cuyo art. 117 señala que "los ancianos merecen la protección especial del Estado", que "el Estado tiene la obligación de proteger a la infancia" (art. 119 inciso $1^{\circ}$ ) y que "el Estado brindará especial protección a los menores cuyos padres o tutores estén imposibilitados económicamente para proveer a su crianza y educación" (art. 121 inciso 2o); y por la Constitución de República Dominicana que en su art. $55 \mathrm{~N}^{\circ} 11$ señala que "el Estado reconoce el trabajo del hogar como actividad económica que crea valor agregado y produce riqueza y bienestar social, por lo que se incorporará en la formulación y ejecución de las políticas públicas y sociales". 
2.2.4 Dentro de las Constituciones imposibles de clasificar bajo este criterio formal, se aprecia una tendencia directamente proporcional entre un colectivismo "deprimido" y una menor tendencia a las alusiones a la familia como ente abstracto. Por el contrario, el énfasis parece estar dado en las referencias a sus miembros individualmente considerados (padre, madre, hijos). Este es el caso, por ejemplo, de la Constitución nicaragüense que, en el capítulo especial dedicado a los "derechos de la familia" y luego de declarar que la familia es el núcleo fundamental de la sociedad, merecedora de la protección de esta y del Estado; desarrolla su contenido con un enfoque basado en los individuos que conforman la familia. Así, en el art. 71 inciso $1^{\circ}$ consagra "el derecho de los nicaragüenses a constituir una familia"; en el art. 73 habla de las relaciones familiares que "descansan en el respeto, solidaridad e igualdad absoluta de derechos y responsabilidades entre el hombre y la mujer"; en el art. 74 se refiere a que "la mujer tendrá protección especial durante el embarazo y gozará de licencia con remuneración salarial y prestaciones adecuadas de seguridad social"; mientras que el art. 75 dice que "todos los hijos tienen iguales derechos" y el art. 77 indica que "los ancianos tienen derecho a medidas de protección por parte de la familia, la sociedad y el Estado".

\section{3) CONSTITUCIONES CON PRONUNCIAMIENTO EXPRESO ACERCA DEL ROL O POSICIÓN DE LA FAMILIA EN LA SOCIEDAD O SIN PRONUNCIAMIENTO AL RESPECTO, Y CONSTITUCIONES QUE RADICAN LA RESPONSABILIDAD DE LA PROTECCIÓN DE LA FAMILIA EN EL ESTADO O NO}

Este criterio apunta a distinguir aquellas Constituciones que contienen una declaración explícita del rol asignado a la familia en la sociedad o a la posición que ella ocuparía en la organización social, sin perjuicio de que puedan contener, además, una regulación de la familia a propósito de la consagración de los derechos individuales y/o colectivos.

2.3.1 En este marco, priman las Constituciones que contienen una fórmula general acerca del rol o del posicionamiento de la familia en la sociedad. Estas fórmulas generales expresan la idea de la familia como institución o asociación fundante, natural, esencial o nuclear de la sociedad. Constituyen la excepción, aquellas Constituciones que, refiriéndose a la familia, no le asignan una función fundamental en la organización social, como es el caso de la Constitución de Bolivia, Guatemala, Panamá, Honduras, México, y Argentina. 
2.3.2 En relación con el rol asignado por la Constitución al Estado respecto de la familia, la gran mayoría de ellas le atribuyen un rol de garante o protector. Solo Argentina y México le confieren tal función a la ley. En efecto, el art. 14 bis inciso $3^{\circ}$ de la Constitución argentina señala: "En especial, la ley establecerá: ...la protección integral de la familia [...]". A su vez, el art. 4 inciso $2^{\circ}$ de la Constitución mexicana establece que "el varón y la mujer son iguales ante la ley. Esta protegerá la organización y el desarrollo de la familia”. En una situación especial se ubica la Constitución paraguaya, dado que en su art. 49 se contenta con señalar que "se promoverá y se garantizará su protección (de la familia) integral".

2.3.3 Relacionando ambas tendencias, resulta que casi todas las Constituciones que definen el rol o posición que la familia debe cumplir, establecen, al mismo tiempo, el deber del Estado de proteger a la misma; salvo Guatemala, Honduras y Panamá que, aún sin fijarle un rol o posición a la familia en la sociedad, le confieren al Estado la posición de garante a su respecto. Por otra parte, solo México y Argentina no le asignan rol o posición alguna a la familia y le confieren competencia a la ley para su protección.

\section{3) Sistematización de las Constituciones en AMÉrica latina. TENDENCIAS EN EL PLANO MATERIAL}

El análisis de las Constituciones desde el punto de su contenido regulativo arrojó los resultados que se detallan más abajo, en función de cada criterio.

\section{1) CONSTITUCIONES EN QUE LOS CONCEPTOS DE FAMILIA $Y$ MATRIMONIO ESTÁN DESVINCULADOS Y CONSTITUCIONES EN QUE LA FAMILIA SE CONFUNDE CON EL MATRIMONIO}

Este criterio tiene por objeto agrupar las Constituciones estudiadas entre aquellas que desvinculan los conceptos de familia y matrimonio; y aquellas en que, por el contrario, ambos conceptos aparecen esencialmente vinculados. En el primer grupo, la separación entre los conceptos de familia y matrimonio permite concluir que en la voz familia quedan amparados distintos modelos o formas de la misma y, en cambio, en el segundo grupo, la protección constitucional se reduce únicamente a la familia matrimonial, ya que se asimilan los conceptos de familia y matrimonio. En todo caso, vale la pena precisar, que el que una Constitución desvincule ambos conceptos no implica que ella no contenga normas especiales para el matrimonio. En un tercer grupo se encuentran aquellas Constituciones 
que no emiten un pronunciamiento al respecto. De esta omisión, se podría colegir que ellas acogen la desvinculación entre familia y matrimonio o que asimilan ambos conceptos. Siendo esto último una materia de interpretación, se prefirió agruparlas de forma separada.

La desvinculación entre familia y matrimonio se puede manifestar en cualquiera de las siguientes tendencias o en ambas: equiparación de todas las clases de filiación y reconocimiento de formas familiares alternativas a la matrimonial.

3.1.1 En general, el examen de las Constituciones arroja que las normas sobre igualación de los hijos son mucho más fuertes e inequívocas que aquellas relativas a distintas formas de familia. Incluso, algunas Constituciones llegan a igualar la filiación adoptiva (Brasil), a la asistida (Colombia) y la aplicación igualitaria de la presunción de paternidad del marido a la filiación no matrimonial (Ecuador).

3.1.2 La igualación de hijos va normalmente unida a una cláusula de prohibición de discriminar y de dejar rastro del nacimiento del hijo. De esta manera, se refuerza la equiparación.

3.1.3 En lo tocante al matrimonio, hay grados en cuanto a las referencias. Algunas Constituciones solo lo definen, otras establecen un mandato general a la ley para que regule sus distintos aspectos, y otras, incorporan detalles de su regulación como, por ejemplo, Guatemala que se refiere a los funcionarios competentes para la celebración del matrimonio.

3.1.4 Un caso especial lo constituye Paraguay, que incluye a los abuelos en el concepto de familia. Sería el único caso en que expresamente se alude a la familia extendida.

3.1.5 Algunas Constituciones que no tienen norma de equiparación de filiaciones tienen, sin embargo, mención expresa en cuanto a la protección de la maternidad, sin distingo entre mujer casada y soltera. Parece razonable concluir que una tal regulación desemboca en la igualdad de los hijos.

3.1.6 En las menciones a las uniones de hecho destaca que la mayoría se refiere expresamente a las heterosexuales, llegando, incluso, a prohibir las uniones homosexuales. Solo la Constitución de Honduras contempla explícitamente la unión homosexual.

3.1.7 La equiparación de la familia matrimonial a la no matrimonial, cuando no está expresada, tiene matices. En algunos casos, al conferir mandato a la ley para regularlas, no se sabe si, en definitiva, existe equiparación material o no. En el caso de Perú, la equiparación expresa solo se refiere a los aspectos patrimoniales de la unión.

3.1.8 En el caso de Costa Rica, no aparece con claridad si la unión de hecho está incluida en la protección que se le entrega a la familia 
porque el art. 52 indica que "el matrimonio es la base esencial de la familia y descansa en la igualdad de derechos de los cónyuges", con lo cual, pareciera excluir cualquier otro fundamento, distinto del matrimonio, como presupuesto de la familia. Otro tanto ocurre con Guatemala que, a pesar de contener norma expresa en cuanto a la equiparación de los hijos (art. 50) y un reconocimiento de las uniones de hecho (art. 48), establece que "el Estado garantiza la protección social, económica y jurídica de la familia. Promoverá su organización sobre la base legal del matrimonio, la igualdad de derechos de los cónyuges, la paternidad responsable y el derecho de las personas a decidir libremente el número y espaciamiento de sus hijos". La segunda parte de la disposición da pie para sostener que la protección debida a la familia matrimonial sería distinta de la debida a la no matrimonial.

\section{2) CONSTITUCIONES CON MENCIÓN EXPRESA A LA DISOLUBILIDAD DEL MATRIMONIO Y SIN DICHA MENCIÓN}

Esta clasificación atiende a si las Constituciones consagran expresamente la disolubilidad del matrimonio o, por el contrario, no se refieren a ese aspecto, sea que le confieran un mandato a la ley para regular todo lo concerniente al matrimonio o no.

3.2.1 De las Constituciones analizadas, resulta que 9 de ellas tienen una disposición referida a la disolución del matrimonio y 10 no la tienen. No tienen mención expresa en cuanto a la disolubilidad del vínculo matrimonial las Constituciones de Haití, El Salvador, Guatemala, Ecuador, Venezuela, República Dominicana, Argentina, Costa Rica, Uruguay y México. Interesante resulta establecer que de estos países, solo Argentina omite completamente la institución del matrimonio y, en cambio, los demás países sí aluden con mayor (El Salvador, Guatemala, República Dominicana, Costa Rica) o menor (Haití, Ecuador, Venezuela y Uruguay) amplitud y énfasis a él pero sin pronunciarse sobre su disolución. Por otra parte, coincide que las Constituciones que mayor fuerza dan al matrimonio, a través de disposiciones como "el Estado fomentará el matrimonio" (art. 32 inciso $2^{\circ}$ Constitución de El Salvador), "promoverá su organización sobre la base legal del matrimonio" (art. 47, $2^{\circ}$ frase Constitución de Guatemala), "promoverá y protegerá la organización de la familia sobre la base de la institución del matrimonio entre un hombre y una mujer" (art. 55 n³ Constitución de República Dominicana) o "el matrimonio es la base esencial de la familia" (art. 
52 Constitución de Costa Rica); no se refieren a la disolución del matrimonio. Muchas de las Constituciones que contienen mención expresa referida a la disolución del matrimonio, tienen una remisión general a la ley para que sea ella la que regule el derecho matrimonial. Así, Colombia, Cuba, Nicaragua, Panamá, Paraguay y Perú confieren un mandato al legislador para regular el matrimonio y su disolución.

3.2.2 Solo la Constitución de Brasil alude más detalladamente a la disolución del matrimonio a través del sistema de divorcio por cese de la convivencia y, en cambio, ninguna Constitución se refiere al sistema de divorcio por culpa. El resto de las disposiciones constitucionales hacen una referencia general al divorcio o a la disolución del matrimonio, sin mayor especificación.

3.2.3 La mayoría de las Constituciones que declaran la disolubilidad del matrimonio tampoco se pronuncia sobre si el divorcio debe ser de común acuerdo entre los cónyuges o unilateral, salvo Nicaragua que en su art. 72 señala que el matrimonio podrá disolverse "por mutuo consentimiento o por la voluntad de una de las partes".

3.2.4 En general, las disposiciones constitucionales que hacen mención al divorcio aluden directamente a la extinción del vínculo matrimonial, al matrimonio "en abstracto". Sin embargo, excepcionalmente, la alusión se hace a propósito de los hijos, como ocurre en la Constitución de Bolivia que se refiere a la "separación" de los cónyuges (situación más amplia que la del divorcio pero que comprende también esta hipótesis) y señala que en este caso "la situación de los hijos se definirá teniendo en cuenta el mejor cuidado e interés moral y material de estos" (art. 196, $2^{\text {a }}$ frase).

3.2.5 Solo se refiere a la nulidad del matrimonio la Constitución colombiana (art. 42 inciso $10^{\circ}$ ), a propósito de las sentencias de nulidad de los matrimonios religiosos dictadas por las autoridades de la respectiva religión.

3.2.6 La consagración constitucional de la disolubilidad del matrimonio repercute en la fuerza que tiene la protección de la familia matrimonial, sea que ella esté expresamente establecida o quede incluida en la protección general de la familia, en la medida que esta forma de familia queda entregada a la esfera de disposición individual. En efecto, en la medida que el matrimonio se reconoce disoluble, dependerá de sus partes ponerle término, rasgo que le resta estabilidad y la acerca a lo que tradicionalmente se ha entendido que caracteriza a la unión de pareja no formalizada a través del matrimonio. Lo anterior plantea, además, la cuestión acerca del estatus de aquellos matrimonios que, divorciándose, 
tienen hijos en común. De si ellos con posterioridad al divorcio continúan formando familia.

\section{3) DESMANTELAMIENTO DEL MODELO DE FAMILIA PATRIARCAL}

Esta tendencia -como se indicó previamente- supone la existencia de procesos de individuación en el seno de la familia, tanto respecto de las mujeres como de los niños que se enmarcan, a su turno, en procesos de igualación de estos sujetos respecto de la figura del Jefe de Familia y en procesos de especificación de derechos que dan origen a nuevos titulares y una expansión de derechos. Para caracterizar esta tendencia se utilizaron, entonces, los siguientes subcriterios de sistematización: (3.3.1.) Normas sobre derechos y protección del Niño, (3.3.2.) Normas sobre derechos de la mujer y protección de la maternidad, (3.3.3.) Normas sobre derechos y protección de otros sujetos, (3.3.4.) Normas relativas al establecimiento de relaciones de igualdad entre mujeres y hombres en el marco de la familia; y (3.3.5.) Normas relativas al establecimiento de relaciones de igualdad referidas a la filiación.

\subsubsection{Normas sobre derechos y protección del Nińo}

3.3.1.1 De los 19 textos constitucionales examinados, 17 contienen normas que se refieren específicamente a la situación de los niños, con énfasis variables en cuanto a la consideración del niño como objeto de protección o como sujeto de derechos. En esta última vertiente destaca la Constitución ecuatoriana que contempla, incluso, el derecho de los niños "a la participación social, al respeto de su libertad y dignidad, y a ser consultados en los asuntos que les afecten" (art. 49). Mientras que como ejemplo de una regulación con componentes tutelares puede mencionarse el art. 60 de la Constitución boliviana que utiliza expresiones como protección y socorro. La Constitución paraguaya, en cambio, a pesar de utilizar en el título respectivo la expresión "de la Protección al Niño" (art. 54) construye dicha protección bajo una técnica obligacional, esto es, con una configuración propia de los derechos subjetivos, situando a los niños como titulares de estos derechos y a la familia, la sociedad o el Estado, como sujetos obligados. Sin embargo, la mayoría de los textos estudiados, mezcla las aproximaciones antes descritas consignando, por una parte, los derechos de los niños y, por la otra, directrices o habilitaciones para que los poderes públicos implementen políticas de protección. 
3.3.1.2 Entre los derechos de los niños mencionados por los textos constitucionales analizados se encuentran los derechos a la vida, la integridad físico-psíquica, la educación, la cultura, la salud, la nutrición, la seguridad social, la identidad, el nombre, la ciudadanía o la nacionalidad, el recreo y el esparcimiento. Es decir, el crisol cubre derechos civiles, políticos y sociales. La Constitución haitiana constituye una excepción al establecer como derechos, en su art. 261, el amor, el afecto y la comprensión. Considerando el contenido de estos "derechos", la disposición parece tener un sentido más retórico que normativo.

3.3.1.3 En el ámbito tutelar, puede observarse el desarrollo de una técnica de protección general que se combina con una protección reforzada dada la situación de vulnerabilidad asociada a la infancia y con una protección especial en caso de ocurrencia de ciertas contingencias. Son ejemplos del segundo tipo de protección descrita, la protección ante la violencia, la explotación y el abuso sexual (ej. Guatemala, Haití, Honduras), mientras que son ejemplos de protección ante contingencias, la protección en caso de orfandad y abandono (ej. Brasil, Paraguay y Colombia). Por otra parte, a la protección de la infancia, se suma la de la adolescencia como categoría diferenciada (ej. Ecuador, Nicaragua, Uruguay) y la protección de los niños discapacitados (Haití).

3.3.1.4 Finalmente, merece destacarse la incardinación de la protección internacional del niño y de la nińa, de manera más o menos explícita, en las Constituciones latinoamericanas. Esto se hace a través de cuatro modalidades: a) incorporación expresa de la Convención de Derechos del Niño (Argentina, Nicaragua y Venezuela), incorporación tácita a través de la referencia genérica a la protección contenida en tratados o acuerdos internacionales (Colombia y Honduras); y c) constitucionalización del principio de Interés Superior del Niño. Esto último, a su vez, puede hacerse bajo la utilización expresa de esta fórmula semántica (Bolivia, Ecuador, Uruguay, República Dominicana) o sobre la base del establecimiento de una preferencia por los derechos del niño en caso de conflicto con otros derechos (Colombia, Paraguay).

\subsubsection{Normas sobre derechos de la mujer y protección de la maternidad}

3.3.2.1 De las 19 Constituciones analizadas, 17 contienen normas que se refieren, directa o indirectamente, a la protección de derechos de la mujer. De estas, la gran mayoría corresponde a normas de protección de la maternidad. Solo cuatro Constituciones 
contienen protección respecto de la violencia doméstica (Bolivia, Colombia, Ecuador y República Dominicana) y, dentro de estas, solo Ecuador se refiere determinadamente a la mujer, sin excluir la protección de otros sujetos, mientras que la Constitución de la República Dominicana se refiere a la violencia intrafamiliar y a la violencia de género, determinadamente (art. $\left.42 . n^{\circ} 2\right)$. la Constitución de Argentina no contiene una referencia clara de protección a la mujer, pero contiene un reenvío específico a la CEDAW, tratado al que le otorga jerarquía constitucional en el art. 22 inciso $2^{\circ}$.

3.3.2.2 Sin perjuicio de las normas de igualación de derechos que se analizan en la sección siguiente, la protección de la maternidad actúa como el foco de interés del Derecho Constitucional en lo concerniente al rol o posición de la mujer en la familia. Esta protección, sin embargo, adopta distintas configuraciones. Esta cuestión puede analizarse desde una perspectiva formal y desde una perspectiva material.

3.3.2.3 Desde una perspectiva formal, se detectan: a) declaraciones generales de contenido indeterminado (Bolivia, Costa Rica, Ecuador, El Salvador, Haití, Panamá y República Dominicana), es decir, se trata de declaraciones que involucran un compromiso de protección estatal de la maternidad, sin determinar en qué consiste este. Evidentemente, la concreción de dicho compromiso requiere un desarrollo normativo posterior en sede legal y/o reglamentaria; y b) desarrollo normativo más detallado (Brasil, Colombia, Nicaragua, Paraguay).

3.3.2.4 Desde el punto de vista material pueden detectarse varias orientaciones normativas. En general, estas se aprecian en aquellos textos que contienen, según hemos indicado, un desarrollo normativo más detallado. Sin embargo, en el caso de Haití y a pesar de tratarse de una Constitución que se encuadra dentro del primer tipo de regulación, es decir, con declaraciones generales, el lenguaje utilizado (el Estado debe "procurar ayuda y asistencia a la maternidad") parece indicar una orientación de tipo asistencialista. Lo propio ocurre con la Constitución de República Dominicana que se refiere al "derecho a asistencia oficial en caso de desamparo" (art. $55 \mathrm{n}^{\circ} 6$ ).

3.3.2.5 Sin perjuicio de lo apuntado en el caso de Haití, las orientaciones sustantivas detectadas son las siguientes: a) Regulación tutelar general de la maternidad sin determinación de ámbito específico (Costa Rica, Ecuador, El Salvador, Panamá y República Dominicana); b) Protección de la maternidad en el marco de derechos reproductivos y políticas de planificación familiar (Bo- 
livia, Nicaragua, Paraguay, Venezuela); y c) Protección de la maternidad en el ámbito laboral (Bolivia, Brasil, México, Nicaragua). Así, los textos brasileńo y mexicano parecen inclinarse por una regulación que enfatiza la protección del empleo, es decir, la protección de la maternidad operaría como garantía de derechos laborales. La Constitución de Nicaragua, en contraste, suma a su orientación tutelar de la maternidad en el ámbito laboral, la orientación reproductiva referida en el párrafo anterior. Esta hibridación parece generar una inclinación ligeramente diversa. En efecto, la norma que prohíbe "negar [un] empleo a las mujeres aduciendo razones de embarazo" podría interpretarse como un incentivo dirigido a la conciliación entre la vida familiar y laboral, o en su defecto, bajo una óptica de derecho antidiscriminatorio. Y d) Protección de todo tipo de maternidad (República Dominicana, Uruguay, Venezuela). Las expresiones utilizados en el caso de la Constitución uruguaya que se refiere a "la maternidad, cualquiera sea la condición o estado de la mujer", y en la Constitución venezolana que advierte que "la maternidad y la paternidad son protegidas integralmente, sea cual fuere el estado civil de la madre o del padre", sugieren que se busca contrarrestar un efecto de exclusión de lo que pudiéramos denominar las "maternidades atípicas". Lo propio ocurre en el caso de República Dominicana que garantiza la protección de la maternidad "cualquiera sea la condición social o el estado civil de la mujer". Parece ser, entonces, que estas normas tienen un propósito de igualación dirigido a supuestos de maternidad no amparados por la cobertura legal y/o la legitimidad social proveniente del matrimonio, es decir, fundamentalmente a las madres solteras.

\subsubsection{Otros sujetos protegidos}

3.3.3.1 De los 19 textos analizados, 13 dan cuenta del surgimiento de otros sujetos de derechos y/o destinatarios de protección. Además de la protección a la adolescencia o juventud como categoría diferenciada (fenómeno que se destacó a propósito de la protección de los derechos de los nińos), se agregan otros dos nuevos sujetos: los ancianos o adultos mayores (Bolivia, Brasil, Colombia, Costa Rica, Cuba, Ecuador, Guatemala, Haití, Nicaragua, Panamá, Paraguay, Perú, República Dominicana y Venezuela) y las personas con discapacidad (Bolivia, Costa Rica, Ecuador, Guatemala, Paraguay, Perú, República Dominicana y Venezuela). Cabe mencionar que la Constitución boliviana dedica una sección específica (sección V) a los derechos de la niñez, 
la adolescencia y la juventud en los que distingue determinadamente a niños y niñas; y que lo propio hace la Constitución de República Dominicana en su art. 58.

3.3.3.2 Este fenómeno de diferenciación de sujetos puede encuadrarse dentro de uno de los procesos centrales de la historia de los derechos fundamentales, el proceso de especificación de derechos fundamentales. Desde una perspectiva de género, en cambio, tiene un componente adicional: es la consecuencia directa de la erosión del modelo femenino de cuidadora y la correlativa redefinición del rol estatal en materia de gestión de la dependencia, según se explicó en la primera parte de este trabajo. Los textos constitucionales latinoamericanos, si bien se nutren de filosofías regulativas variopintas en relación con actividad prestacional del Estado, parecen admitir, al menos como premisa de regulación, que la familia ya no actúa como la prestadora de cuidado por antonomasia y que su actividad debe, a lo menos, complementarse por el Estado. Ilustra esta posición el art. 80 de la Constitución venezolana que establece claramente que los derechos de los ancianos deben ser garantizados por "el Estado, con la participación solidaria de las familias y la sociedad”.

\subsubsection{Relaciones igualitarias entre hombre y mujer en el marco de la familia}

3.3.4.1 Catorce de los textos examinados contienen disposiciones expresas de igualación de derechos entre hombres y mujeres en el ámbito de la familia. A estos puede sumarse Argentina a través del reenvío que contiene su Carta Fundamental a la CEDAW. La igualdad de derechos entre cónyuges se expresa a través de (a) una cláusula general de igualdad de derechos aplicada al ámbito de la familia (Bolivia, Costa Rica, Honduras, México, Panamá) o mediante (b) la determinación específica de los aspectos sobre los que recae dicha igualdad. Siguen esa última aproximación Brasil, Colombia, Cuba, Ecuador, El Salvador y Nicaragua.

3.3.4.2 Esta determinación de aspectos evidencia énfasis diferenciados. En algunos casos se trata de la igualación en el régimen patrimonial (Brasil, El Salvador) y/o la igualdad se aplica, en general a las relaciones personales entre hombre y mujer, esto es, aquellas que se crean y se desarrollan en el ámbito privado-familiar.

3.3.4.3 En otros casos la igualdad se proyecta más allá del ámbito familiar y parece nuevamente engarzarse con la vida laboral. Esto ocurre en aquellos textos que se refieren a la igualdad de oportunidades (Colombia, Ecuador) o en el caso del art. 7 de la Cons- 
titución de Brasil que alude a la licencia de paternidad. Especial mención requiere también la Constitución ecuatoriana que contiene una manifestación clara de mainstreaming, en su art. 41, al establecer que en la ejecución de las políticas de igualdad de oportunidades entre hombres y mujeres se "incorporará el enfoque de género en planes y programas, y brindará asistencia técnica para su obligatoria aplicación en el sector público".

3.3.4.4 También pueden interpretarse bajo una perspectiva de género aquellas disposiciones que establecen la corresponsabilización de hombres y mujeres en las tareas de manutención del hogar y cuidado de los niños (Cuba, Ecuador y Nicaragua), puesto que parecen incentivar un intercambio recíproco o solapamiento de roles de género. Esta tendencia es todavía más apreciable si se complementa este criterio con los dos criterios siguientes, es decir, con las normas de igualación en materia de filiación y con la configuración de los derechos reproductivos que, como se verá, involucran implícitamente una corresponsabilización en la crianza de los hijos y en las decisiones de planificación familiar.

\subsubsection{Relaciones igualitarias en materia de filiación}

3.3.5.1 De las 19 cartas fundamentales estudiadas, 15 contienen disposiciones explícitas de igualación entre hijos matrimoniales y no matrimoniales, en relación con las obligaciones que los mismos textos establecen entre padres e hijos. De estos textos constitucionales, 10 (Costa Rica, Cuba, Ecuador, El Salvador, Honduras, Nicaragua, Panamá, Paraguay, Perú y República Dominicana) prohíben expresamente, además, las menciones diferenciadas en materia de filiación en Registros y/o documentos personales.

\section{4) DERECHOS REPRODUCTIVOS}

3.4.1 De las 19 Constituciones examinadas, 9 consagran, de manera expresa, la existencia de los llamados derechos sexuales y reproductivos, los que son atribuidos invariablemente a las personas sin distinción de sexo, salvo en el caso de Colombia que se refiere a "la pareja".

3.4.2 Cabe mencionar que las técnicas de construcción de estos derechos, desde el punto de las relaciones jurídicas implicadas, son distintas. En algunos casos se regula estos derechos como una libertad o derecho no interferencia (Bolivia, Colombia, Guatemala, México, Perú) que impide al Estado (y por extensión 
a terceros) interferir con las decisiones relativas al número y espaciamiento de los hijos, mientras que en otros se agrega una dimensión prestacional que los transforma en una suerte de derechos-crédito o prestacionales (Brasil, Ecuador, Paraguay, Venezuela). En este último enfoque, el contenido de la prestación a la que se obliga el Estado puede consistir en el suministro de información y/o de recursos científico-técnicos para el ejercicio material de esos derechos.

3.4.3 No obstante, sobre todo en los textos que regulan estos derechos bajo una configuración de libertad no interferencia, no existe ninguna regulación expresa sobre la interrupción voluntaria del embarazo, por lo que dichos derechos bien puede interpretarse circunscritos a la anticoncepción.

\section{5) INTERNACIONALIZACIÓN DE LA PROTECCIÓN DE LA FAMILIA Y DE LOS DERECHOS DE SUS MIEMBROS}

\subsubsection{Apuntes preliminares sobre el proceso de internacionalización de la protección de la familia}

Dado el fenómeno de internacionalización de la regulación de la familia y la presencia de normas de recepción de tratados en las Constituciones de la región americana y, particularmente de normas de reenvío, conviene hacer una digresión sobre el régimen de protección convencional internacional de la familia, tanto en el ámbito del sistema universal de protección de derechos humanos como en el sistema regional americano. El listado de derechos pertinentes incluye: a) El derecho de casarse y fundar una familia, b) Igualdad de derechos del hombre y la mujer en el marco de la familia, c) El derecho de contraer matrimonio con libre y pleno consentimiento, d) Derechos sexuales y reproductivos, e) El derecho del niño al cuidado de sus padres, y f) la Protección a la maternidad.

\subsubsection{Instrumentos internacionales para la protección y promoción de la familia}

A continuación se reseña algunos de los instrumentos internacionales relevantes que estos derechos, así como otras disposiciones relevantes sobre la familia.

\subsubsection{Sistema de Naciones Unidas.}

3.5.2.2 Declaración Universal de los Derechos Humanos. El artículo 16 define a la familia como la unidad natural y fundamental de la sociedad. Establece el derecho del hombre y de la mujer para 
casarse y fundar una familia, el derecho a la igualdad en el matrimonio y el libre consentimiento en este.

3.5.2.3 Pacto Internacional de Derechos Económicos, Sociales y Culturales. El artículo 10 reconoce derechos humanos básicos en lo que concierne a la vida familiar y profundiza en los derechos de las madres embarazadas, las licencias por maternidad y la seguridad social.

3.5.2.4 Pacto Internacional de Derechos Civiles y Politicos. El artículo 23 garantiza el derecho a la familia señalando en su numeral primero que la familia es el grupo-unidad natural y fundamental de la sociedad y tiene el derecho a ser protegido por la sociedad y el Estado. En el número 2 se consagra que el derecho de cada hombre o mujer de contraer matrimonio y de fundar una familia será reconocido, mientras que el número 3 establece que ningún matrimonio se contraerá sin libre y pleno consentimiento de los futuros cónyuges. El número 4 contiene la obligación para los Estados partes de adoptar medidas adecuadas para asegurar la igualdad de los derechos y responsabilidades de los futuros cónyuges antes, durante el matrimonio, y en caso de disolución del mismo. En el caso de este último, deberán tomarse medidas adecuadas para la protección necesaria de cualquier hijo.

3.5.2.5 La Convención sobre la eliminación de todas las formas de discriminación contra la Mujer. Esta contiene un dispositivo normativo de derecho antidiscriminatorio que protege a la mujer, incluida su posición social en la familia. Incluye previsiones sobre el matrimonio y la nacionalidad (artículo 9); igualdad y libre consentimiento; derechos y responsabilidades dentro del matrimonio, planificación familiar; maternidad y adopción; el derecho de la mujer a escoger el nombre de familia, profesión y trabajo; propiedad; edad mínima para casarse y el estricto registro del matrimonio (artículo 16).

3.5.2.6 Convención sobre los Derechos del Niño. La Convención sobre los Derechos de los Niños se refiere a la separación del niño de sus padres (artículo 9), la reunificación familiar (artículo 10 y 22) y las medidas para los niños que carecen cuidado de sus padres (artículos 20 y 21).

3.5.2.7 La Convención internacional sobre la protección de los derechos de todos los trabajadores migratorios y de sus familiares. Este tratado, que viene a engrosar el plexo normativo del sistema universal, regula expresamente la situación de los trabajadores migratorios y de los "miembros de su familia" quienes son caracterizados como aquellas "personas casadas con los migrantes, o que tienen una relación que, por ley, es equivalente a un matrimonio, tanto como a sus hijos dependientes, así como otras personas dependientes que hayan sido reconocidas como miembros de la 
familia por ley o acuerdos bilaterales o multilaterales entre los Estados miembros" (artículo 4). Este tratado establece que los Estados "deben considerar ofrecer trato igual, como se dicta en el párrafo 2 del presente artículo, a los otros miembros de familia de los trabajadores migrantes" (artículo 44); que los miembros de la familia de los trabajadores migrantes deberán disfrutar igualdad en el trato que las familias nacionales con respecto al acceso a la educación, servicios sociales y sanidad y la participación en la vida cultural, y que el Estado debe facilitar la integración de los hijos de los trabajadores migrantes en el sistema local de educación, particularmente la enseñanza del idioma local, la lengua materna y la cultura (artículo 45). Finalmente, esta Convención estipula que, en caso de muerte del trabajador migrante o disolución del matrimonio, el Estado receptor debe considerar otorgar la carta de residencia a los miembros de familia del trabajador migrante (artículo 50).

\subsection{3) Sistema Americano de Derechos Humanos}

3.5.3.1 Convención Americana sobre Derechos Humanos. La Convención declara que "la familia es la unidad natural y elemental de la sociedad, y debe recibir protección, tanto de la sociedad, como el apoyo del Estado". Reconoce el derecho de "cada hombre o mujer de casarse y fundar una familia si se reúnen las condiciones requeridas por las leyes nacionales y dichas condiciones no afectan el principio de no discriminación". Asimismo, establece que el matrimonio requiere libre y pleno consentimiento de los futuros cónyuges, supone la igualdad de derechos y de las responsabilidades de los esposos durante el matrimonio y en el caso de disolución de este, asegura la igualdad de derechos de los niños nacidos dentro y fuera del matrimonio.

3.5.3.2 Convención Interamericana para prevenir y erradicar la violencia de género o Convención de Belém do Pará. Contiene normas sobre erradicación de la violencia de género, tanto en la esfera privada-familiar como en la esfera pública.

\section{6) Normas constitucionales de reenvío al Derecho INTERNACIONAL}

En esta sección se utiliza el modelo de bloque de constitucionalidad $y$, por ende, se consideraron relevantes las normas constitucionales de reenvío al Derecho Internacional y las disposiciones que regulan la jerarquía de los tratados internacionales. Estas dos categorías de normas permiten el ingreso de la regulación internacional de la familia establecida en 
tratados internacionales y que ha sido referida previamente, así como su prevalencia en caso de conflicto con reglas internas, en su caso.

3.6.1 Dentro de las primeras, puede observarse la existencia de Constituciones que contienen una cláusula general de reenvío al derecho internacional convencional, con referencia o no a normas de derechos humanos (Colombia, Perú, República Dominicana y Venezuela), y cláusulas de reenvío a tratados específicos (Argentina, Nicaragua, Colombia). Generalmente estas últimas contienen, además, un dispositivo de jerarquía reforzada de los tratados, como ocurre en el caso del texto argentino que establece que los tratados específicamente mencionados en su art. 22 tienen jerarquía constitucional. Entre estos, como ya lo hemos apuntado, se incluyen la Convención sobre Derechos del Nińo y la CEDAW. En el caso de Nicaragua, la Convención sobre los derechos del Nińo, si bien no está contenida en el catálogo del art. 46, resulta incorporada al derecho nicaragüense con sujeción al reenvío expreso realizado por el art. 71. Algo similar ocurre con la Constitución venezolana que le presta a esta convención una atención especial.

3.6.2 En relación con las reglas de jerarquía, además del caso argentino merecen mención especial el caso guatemalteco y el boliviano. El art. 46 de la Constitución de Guatemala establece una regla de preeminencia del Derecho Internacional convencional de Derechos Humanos sobre todo el Derecho Interno de Guatemala, esto es, una jerarquía supraconstitucional. Lo propio hace la Constitución de Bolivia en su art. 256. Sin perjuicio de la constitucionalización del principio de Interés Superior del Nińo, fenómeno al que nos referimos a propósito de la protección constitucional de derechos del niño, puede apreciarse que la mayoría de los textos constitucionales de la región se decanta por el establecimiento de reglas que otorgan un valor reforzado a los tratados respecto de las leyes, es decir, perfilan un sistema de jerarquía supralegal de tratados (Colombia, Ecuador, El Salvador, Honduras). Como consecuencia de lo anterior, se produce una suerte de congelamiento de la legislación en materia de familia, en todos aquellos aspectos que sean regulados por tratados internacionales que resulten vinculantes para cada Estado.

\section{CONCLUSIONES}

1. Pareciera existir una correlación entre maximalismo y reciente data de las Constituciones. Es decir, en la medida que las Constituciones 
han sido promulgadas más recientemente, la tendencia es hacia una regulación más exhaustiva de la familia, lo que explica el alto número de textos constitucionales maximalistas en el ámbito latinoamericano.

2. La gran mayoría de las Constituciones latinoamericanas contiene normas de regulación de la familia en el marco del tratamiento de los derechos sociales.

3. La consagración de un rol específico para la familia constituye la regla general dentro de las Constituciones latinoamericanas y pareciera existir una coincidencia entre Constituciones maximalistas y aquellas que consagran un rol para la familia en la organización social.

4. La desvinculación de los conceptos de familia y matrimonio, manifestada en la equiparación de las filiaciones y/o en el reconocimiento de distintos modelos familiares, constituye la regla general en las Constituciones latinoamericanas, con lo que se refleja un progresivo reconocimiento constitucional de la diversificación de la familia. En cuanto a la mención constitucional sobre la disolución del matrimonio, en Latinoamérica existe un considerable número de textos que se refieren a ella (9 de 19). Esta regulación podría interpretarse como la profundización constitucional de una estrategia de recogida del cambio social instaurada hasta ahora solo a nivel legal.

5. En el plano sustantivo o material, las Constituciones latinoamericanas reflejan un fortalecimiento de los procesos de individuación de niños y mujeres, a través de la presencia de normas de igualación entre hombres y mujeres, por un lado, e hijos, por el otro. Asimismo, se observa el surgimiento de nuevos sujetos y/o destinatarios de protección, tales como los ancianos y los discapacitados; y una diversificación de la protección que distingue la infancia, la adolescencia y la juventud. Todo ello refuerza un proceso regional de desmantelamiento de la familia patriarcal.

6. También se observa una tendencia incipiente hacia el establecimiento y regulación de los derechos sexuales y reproductivos, que en ocasiones se configuran como libertades y en otras como derechos prestacionales. Esta tendencia, no parece desbloquear por sí sola, sin embargo, las restricciones legales a la interrupción voluntaria del embarazo las que, a falta de un contenido indubitado a nivel constitucional, parecen reconducirse exclusivamente a la anticoncepción. Por otra parte, conviene apuntar que la constitucionalización del principio del interés superior del niño podría favorecer la tesis constitucional de la personalidad del embrión, sin perjuicio de que esta no ha sido avalada explícitamente ni por órganos de supervisión de tratados ni por Cortes internacionales. Con todo, este nuevo diseño aporta elementos para la judicialización constitucional de las regulaciones prohibitivas del aborto. 
7. En el nivel de internacionalización de la protección de la familia, se aprecia que las Constituciones latinoamericanas contienen numerosas normas de reenvío y/o recepción del derecho internacional. Esta situación puede explicarse, una vez más, en atención a que se trata de textos relativamente jóvenes, dado que la constitucionalización de tratados internacionales es también un fenómeno relativamente reciente. Lo anterior, combinado con la existencia de dispositivos constitucionales de jerarquía reforzada de los tratados, implica una especial resistencia de la regulación internacional de la familia frente a los cambios legislativos.

8. En cuanto a la protección de la maternidad, las Constituciones latinoamericanas se caracterizan por un amplio desarrollo de esta protección sobre la base de dos aproximaciones o técnicas de regulación: una protección tutelar genérica y una protección en el marco más amplio de la protección laboral. Esta última técnica puede interpretarse como una fórmula embrionaria de política de conciliación entre vida familiar y vida laboral.

\section{BIBLIOGRAFÍA}

- Barrientos, Javier y Novales, Aranzazú (2004), Nuevo derecho matrimonial chileno, Santiago: LexisNexis, 427 pp.

- Beck, Ulrich y Beck-Gernsheim, Elisabeth (1998). El normal caos del amor. Traducción de Dorothee Schmitz. Barcelona: El Roure Editorial S. A. 292 pp.

- Cánovas, Ana, Aragón, Jorge y Rocha, Fernando (2005) «Las políticas de conciliación de la vida familiar y laboral en las Comunidades Autónomas». Cuadernos de Relaciones Laborales, Vol. 23, núm. 1, pp. 73-93.

- Casas Becerra, L. (1996). Mujeres procesadas por aborto. LOM Eds., Santiago de Chile.

- Corral Talciani, Hernán.

- (1994). «Familia sin matrimonio o familia sin familia» Revista Chilena de Derecho, Vol. $21 \mathrm{~N}^{\circ}$ 2, pp. 259-272.

- (2002). "Claves para entender el Derecho de Familia contemporáneo", Revista Chilena de Derecho, Vol. 29 N 1, pp. 25-34.

- Chávez Asencio, Manuel.

- (1983), "Derechos familiares de la persona y derechos sociales de la familia", Anuario del Departamento de Derecho de la Universidad Iberoamericana, Número 15, 109-139.

- (2001) "La familia y los derechos humanos", en Anuario del Departamento de Derecho de la Universidad Iberoamericana, Número $21,168-185$. 
- (2002) "Derechos familiares fundamentales", en Anuario del Departamento de Derecho de la Universidad Iberoamericana, Número 32, Sección de Previa, pp. 185-201.

- Chávez Hernández, Efrén. "La protección constitucional de la familia; una aproximación a las Constituciones Latinoamericanas, ponencia presentada en el Instituto de Investigaciones Jurídicas de la UNAM, México, disponible en http://www.bibliojuridica.org/ libros/5/2287/9.pdf.

- Eichler, Margrit (1999), "Cambios familiares: familias, políticas e igualdad de género". En Facio, Alda y Fries, Lorena (Eds.), Género y Derecho, la Morada, Santiago de Chile, 444-486.

- Ferrada, Juan Carlos (Coord.). (2003), La Constitucionalización del derecho chileno. Santiago: Editorial Jurídica de Chile, 298 pp.

- Guidens, Anthony (2000). Un mundo desbocado. Los efectos de la globalización en nuestras vidas, Capítulo 4. Madrid: Taurus, pp.6580.

- Gysling, J. (1994) "Salud y derechos reproductivos: conceptos en construcción" en Valdés y Busto (edts). Sexualidad y Reproducción, hacia la construcción de derechos, CORSAPS/FLACSO, Santiago, Chile.

- Henchoz, Caroline (2011). "Les politiques de conciliation familletravail et l'égalité Réflexions sur le concept d'autonomie". Recherches sociologiques et anthropologiques, 42-2, pp. 173-187.

- Htun, Mala (2010), Sexo y Estado. Aborto, divorcio y familia bajo dictaduras y democracias en América Latina. Santiago (Chile): Ediciones Universidad Diego Portales, 278 pp.

- Kemelmajer de Carlucci, Aída (2005) "Codificación y Constitucionalización del Derecho Civil". En Sesquicentenario del Código Civil de Andrés Bello: pasado, presente y futuro de la codificación, Tomo II. Santiago: LexisNexis, 1193-1214.

- Lewis, Jane (2000). "Estado de bienestar y trabajo no remunerado" en De Villota, Paloma (Ed.) La politica económica desde una perspectiva de género. La individualización de los derechos sociales y fiscales en la Unión Europea. Madrid: Alianza Editorial, pp. 55-75.

- Lorenzo Rodríguez, Magdalena (2004) "La conciliación de la vida familiar y laboral en serio: apuntes constitucionales para una conciliación acorde con la igualdad y el principio de no discriminación”, Anuario Jurídico y Económico Escurialense, XXXVII, pp. 73-93.

- López-Muñız, José Luis (2000) "La familia en la Constitución Española”. Revista Española de Derecho Constitucional, No 58 , eneroabril, 2000, pp. 11-43.

- Millard, E., (2005) "Le droit constitutionnel de la famille" en VVAA, Code Civil et constitution economica, París, pp. 65-81. 
- Queniart, A. y Roch, H. «Nouvelles familles, nouveaux défis pour la sociologie de la famille» en Sociologie et sociétés, vol. 30, $\mathrm{N}^{\circ} 1$, primavera 1998, pp. 133-143.

- Rodríguez Ruiz, Blanca.

- (2011). "Matrimonio, Género y Familia en la Constitución Española. Transcendiendo a la familia nuclear". Revista Española de Derecho Constitucional, № 91, enero-abril, pp. 69-102.

- (2012). "Paridad en lo doméstico: entre la normatividad y la realidad”. En Mestre i Mestre, Ruth y Zúńiga, Yanira (Coords.) Democracia y participación politica de las Mujeres. Visiones desde Europa y América Latina. Valencia: Tirant lo Blanch, pp. 11-146

- Schmidt, Claudia. (2005) "La Constitucionalización del derecho de Familia", en Sesquicentenario del Código Civil de Andrés Bello: pasado, presente y futuro de la codificación. Santiago: LexisNexis, Tomo II, pp. $1235-1244$.

- Serna, P. «Crisis de la familia europea: una interpretación» (1994). Revista Chilena de Derecho, Vol. 21 N$^{\circ}$ 2, pp. 233-244. 